DOI: 10.15804/npw20181702

s. $33-44$

www.czasopisma.marszalek.com.pl/pl/10-15804/npw

\title{
Paulina Maria Nowicka
}

Warszawski Uniwersytet Medyczny

\section{Zagrożenia bezpieczeństwa zdrowotnego Ukrainy}

\section{Threats to Ukraine's health security}

\section{Abstract}

Health security is directly proportional to the sovereignty of the state and the abillity to provide health services in its area. Conflicts and wars are inextricably linked to the spread of diseases and the deterioration of health security.

More than three years of conflict in Ukraine has contributed to the occurrence of many health security threats. These include, among others, impeded access to health services (closing at least 160 healthcare facilities) with an increased demand for such services, attacks on medical personnel, lack of access to basic medicines (including the lack of vaccines causing the loss of control over the occurrence of infectious diseases) and medical supplies, the inability of humanitarian aid to reach all the areas controlled by the insurgents.

Threats to Ukraine's health security may have consequences in the form of cross-border threats to public health. They pose challenges faced by the World Health Organization, along with other specialized agencies of the United Nations and partners in providing humanitarian aid.

Keywords: cross-border health threats, conflict in Ukraine, health security 


\section{Угрозы безопасности охраны здоровья Украины}

\section{Аннотачия}

Безопасность здравоохранения является прямо пропорциональна суверенитету государства и способности оказывать медицинские услуги на его территории. Конфликты и войны неразрывно связаны с распространением болезней и ухудшением состояния здоровья.

Более трех лет конфликта в Украине способствовали возникновению многих угроз безопасности здравоохранения. Среди них следует упомянуть затрудненный доступ к медицинским услугам (закрытие как минимум 160 медицинских учреждений) с повышенным спросом на такие услуги, нападения на медицинский персонал, отсутствие доступа к основным лекарственным средствам (включая отсутствие вакцин, что вызывает исчезновение контроля над возникновением инфекционных заболеваний) и предметов медицинского назначения, отсутствие возможности для оказания гуманитарной помощи во всех районах, контролируемых повстанцами.

Угрозы безопасности охраны здоровья Украины могут иметь последствия в виде трансграничных угроз для здоровья населения. Это проблемы, с которыми сталкивается Всемирная организация здравоохранения вместе с другими специализированными организациями и партнерами Организации Объединенных Наций, в оказании гуманитарной помощи. ключевые слова: трансграничные угрозы здоровью, конфликт в Украине, охрана здоровья.

Ключевые слова: трансграничные угрозы для здравоохранения, конфликт в Украине, угрозы безопасности охраны здоровья

B ezpieczeństwo, według tradycyjnej definicji, to wolność od zagrożeń stwarzających niebezpieczeństwo dla przetrwania państwa. Wolność od zewnętrznych zagrożeń osiągano przy pomocy rozwoju zdolności obronnych, co prowadziło do wyścigu zbrojeń (Czaputowicz, 2012, s. 7-8). Wojny jako dominujące źródło zagrożeń w przeszłości kształtowały postrzeganie bezpieczeństwa w kategoriach militarnych (Pawłowski, 2017, s. 39). Przełom w pojmowaniu bezpieczeństwa nastąpił po opublikowaniu pracy Barry'ego Buzana pt. People, States and Fear w 1983 r. Autor przedstawił w niej tezę, że bezpieczeństwo nie odnosi się tylko do państw, ale również do różnego typu ludzkich zbiorowości (Williams, 2012, s. 2-4).

Obecnie wśród naukowców zajmujących się studiami nad bezpieczeństwem pojawiają się spory o to, co należy do sfery bezpieczeństwa. Część 
uważa, że badania powinny dotyczyć konfliktów zbrojnych oraz zagrożeń wynikających z użycia siły wojskowej, inni badacze stawiają na pierwszym miejscu zagrożenia cenionych przez jednostki wartości. Jednak bezpieczeństwo międzynarodowe nie opiera się już wyłącznie na kontroli zbrojeń i prewencji wojny. Kwestie niemilitarne, jak choroby zakaźne, degradacja środowiska, trendy demograficzne i katastrofy humanitarne również stwarzają istotne zagrożenie dla światowego ładu.

Opublikowany przez ONZ w 2004 r. raport pt. A more secure world sprecyzował sześć obszarów zagrożeń dla państw na całym świecie, a były to: konflikty wewnętrzne, konflikty między państwami, broń jądrowa, radiologiczna, biologiczna i chemiczna, terroryzm, zorganizowana przestępczość transnarodowa oraz zagrożenia gospodarcze i społeczne, w tym ubóstwo, choroby zakaźne i degradacja środowiska (Panel Wysokiego Szczebla ONZ, 2004).

Choć przez dziesiątki lat próby odnajdywania punktów stycznych dla dziedzin dotyczących zdrowia oraz badań nad bezpieczeństwem pozostawały bez echa, to już w Konstytucji Światowej Organizacji Zdrowia, uchwalonej 22 lipca 1946 r. w Nowym Jorku, pojawił się zapis że zdrowie wszystkich ludów to podstawa dla osiągnięcia pokoju i bezpieczeństwa (Światowe Zgromadzenie Zdrowia, 1946).

W 1999 r. Centralna Agencja Wywiadowcza dokonała oceny zagrożenia, jakie globalny poziom chorób zakaźnych stanowi dla Stanów Zjednoczonych Ameryki uwzględniając nowe czynniki rozprzestrzeniania się chorób zakaźnych, jak wzrost międzynarodowego przepływu towarów i osób. Zwrócono również uwagę na kwestię zagrożeń, jakie choroby mogą stwarzać dla stabilności ładu międzynarodowego. Autorzy analizy doszli do wniosku, że problem chorób zakaźnych ściśle wiąże się z bezpieczeństwem narodowym (Centralna Agencja Wywiadowcza, 2000). Co więcej, Rada Bezpieczeństwa w przyjętej 17 lipca 2000 r. rezolucji nr 1308 szczegółowo analizując możliwy wpływ HIV/AIDS na funkcjonowanie misji pokojowych ostrzegała, że nieopanowana pandemia HIV/AIDS może stanowić zagrożenie dla stabilności i bezpieczeństwa (Rada Bezpieczeństwa Organizacji Narodów Zjednoczonych, 2000). Zagrożenie zdrowia stało się problemem polityki globalnej i urosło do rangi zagrożenia bezpieczeństwa międzynarodowego. 
Zderzenie dwóch światów: zdrowia i bezpieczeństwa, jakie miało miejsce $\mathrm{u}$ progu nowego milenium, zaowocowało pojawieniem się nowego pojęcia - bezpieczeństwa zdrowotnego (health security). W maju $2001 \mathrm{r}$. ukazało się ono w rezolucji Światowego Zgromadzenia Zdrowia - Global health security: epidemic alert and response. Ostrzeżenia zawarte w rezolucji dotyczyły zjawisk związanych z globalizacją, które mogą być postrzegane jako zagrożenie światowego bezpieczeństwa zdrowotnego. Podkreślono że choroby zakaźne przemieszczają się nie przestrzegając granic państw. Wzmożone ruchy ludności czy to w ramach turystyki, migracji lub jako skutek katastrof czy konfliktów zbrojnych oraz zmiany środowiska połączone z urbanizacją, deforestacją utwierdzały w przekonaniu, że zdarzenia niepożądane dotyczące zdrowia publicznego występujące na terenie jednego państwa mogą stać się zagrożeniem o zasięgu międzynarodowym (Światowe Zgromadzenie Zdrowia, 2001).

Pół roku po ukazaniu się rezolucji Global health security: epidemic alert and response pojawiła się nowa przestrzeń dla bezpieczeństwa zdrowotnego - ministrowie zdrowia Francji, Japonii, Kanady, Meksyku, Niemiec, Stanów Zjednoczonych Ameryki, Wielkiej Brytanii i Włoch stworzyli Inicjatywę na rzecz Światowego Bezpieczeństwa Zdrowotnego (Global Health Security Initiative, GHSI). Inicjatywa była bezpośrednią odpowiedzią na ataki z 11 września $2001 \mathrm{r}$. Był to pierwszy tak doniosły wyraz instytucjonalizacji idei bezpieczeństwa zdrowotnego. Tutaj było ono postrzegane przez pryzmat czyhających zagrożeń biologicznych, chemicznych, radiacyjnych i nuklearnych oraz planu odpowiedzi na nie (Elbe, 2010). Z kolei raport Światowej Organizacji Zdrowia z 2007 r. zdefiniował bezpieczeństwo zdrowotne jako zmniejszoną podatność populacji na ostre zagrożenia zdrowia. Wśród nich wymienił m.in. pandemiczną grypę, katastrofy naturalne, bioterroryzm oraz zdrowotne konsekwencje konfliktów (Światowa Organizacja Zdrowia, 2007).

Ponadtrzyletni konflikt na Ukrainie przyczynił się do wystąpienia wielu zagrożeń bezpieczeństwa zdrowotnego. Wśród nich należy wymienić m.in. utrudniony dostęp do świadczeń zdrowotnych przy zwiększonej ilości zapotrzebowania na takie świadczenia, ataki na personel medyczny, brak dostępu do podstawowych leków (w tym brak szczepionek powodujący zanik kontroli nad występowaniem chorób zakaźnych), brak zaopa- 
trzenia medycznego, brak możliwości dotarcia z pomocą humanitarną do wszystkich obszarów kontrolowanych przez rebeliantów.

Jak powszechnie wiadomo, bezpieczeństwo osoby ratującej jest warunkiem niezbędnym do przystąpienia do udzielania pierwszej pomocy, tymczasem personel medyczny wielokrotnie zgłaszał obawy o własne bezpieczeństwo. Nie wiązały się one jedynie z bezpośrednią pracą w strefie działań zbrojnych, ale wynikały również z zachowań uzbrojonych separatystów wobec niosących pomoc. Mimo wezwań do respektowania neutralności służb medycznych, uzbrojeni separatyści powstrzymywali ich działalność ratowniczą. Pod wpływem gróźb lekarze byli zmuszani do opuszczania stanowisk pracy (Holt, 2014, s. 735). Z doniesień pozarządowej organizacji zajmującej się ochroną praw człowieka - Human Rights Watch wynika, że separatyści rekwirowali ambulanse, używali ich do transportu sił zbrojnych, zastraszali personel medyczny i kradli sprzęt (Human Rights Watch, 2014). Wkraczając do szpitali i klinik przejmowali całe oddziały, aby leczyć własnych poszkodowanych narażając przy tym zdrowie i życie pozostałych pacjentów i personelu (Human Rights Watch, 2015, s. 14-15).

Ogień artyleryjski często uderzał w szpitale (Human Rights Watch, 2017, 24 maja). W sierpniu 2014 r. ucierpiał między innymi szpital w Stanicy Ługańskiej. Podczas kilkugodzinnego ostrzału przebywało w nim 40 osób, w tym 27 pacjentów. Z zeznań świadka zdarzenia wynika, że lekarze i pielęgniarki byli zmuszeni przenieść pacjentów do piwnicy, gdzie przebywali przez całą noc. W wyniku ataku uszkodzono dach $\left(1580 \mathrm{~m}^{2}\right)$, wybito szyby w oknach (669), uszkodzono centralny system ogrzewania, dwie pielęgniarki doznały wstrząśnienia mózgu, jedna - ran odłamkowych. Mimo decyzji zarządu o zamknięciu szpitala, pracownicy nie opuścili swoich stanowisk, blok operacyjny kontynuował działalność, leczono rannych (Justice for peace in Donbas, 2017, s. 2-3).

W sumie 152 szpitale były celem ataków podczas konfliktu, a 67 obiektów ochrony zdrowia zostało zniszczonych. Ponadto trwające walki uniemożliwiały dostarczanie środków medycznych, podczas gdy poszkodowani wymagali leczenia (Biuro Narodów Zjednoczonych ds. Koordynacji Pomocy Humanitarnej, 2017, s. 3-5). Również Lekarze Bez Granic informowali o uzbrojonej grupie, która włamała się do ich siedziby w Doniecku kradnąc trzy oznaczone pojazdy pełne leków (Ukrainian Helsinki Human Rights Union, 2016, s. 9-16). 
Ekipy ratunkowe, trzymane na muszce, poddawane były przeszukaniom w każdym punkcie kontrolnym rebeliantów, co nie tylko wydłużało czas przetransportowania osoby poszkodowanej do szpitala (pomiędzy majem a sierpniem 2016 r. zmarły trzy osoby), ale również było przyczyną ogromnego stresu dla całej ekipy medycznej (Safeguarding Health in Conflict, 2016).

Narody Zjednoczone w sierpniu 2014 r. przekazały, że z obwodu ługańskiego i donieckiego uciekło ok. 70\% pracowników służby zdrowia. $\mathrm{Ci}$, którzy pozostali informowali o rosnącym zagrożeniu związanym z szerzeniem się epidemii gruźlicy (Holt, 2015, s. 494). Ukraina jest jednym z krajów o wysokiej zapadalności na wielolekooporną postać tej choroby (Lekhan i in., 2015, s. 1, 10, 12, 56). Organizacje międzynarodowe, które starają się walczyć z gruźlicą, takie jak Lekarze Bez Granic czy Światowa Organizacja Zdrowia obawiają się, że jej rozprzestrzenianie się może być zwielokrotnione w strefie konfliktu. Brak wczesnej, adekwatnej diagnozy, brak dostępnych leków czy brak osób odpowiedzialnych za prowadzenie leczenia - wszystko to spowolni strategię zwalczania gruźlicy (Światowa Organizacja Zdrowia, 2017).

Konflikt zbrojny niweluje dotychczasowe osiągnięcia w profilaktyce. Do niezwykle istotnych programów profilaktycznych, które ulegają załamaniu należą programy szczepień.

Na przykład przeciwko błonicy, tężcowi i krztuścowi zaszczepionych w 2016 r. było jedynie 42\% dzieci (dla porównania: dzieci zaszczepionych przeciwko tym chorobom było odpowiednio: w Syrii - 61\%, Republice Środkowoafrykańskiej - 69\%, Polsce - 99\%) (Światowa Organizacja Zdrowia, 2017, 22 września). Podobnie niski był poziom zaszczepienia dzieci przeciwko poliomyelitis (ostre nagminne porażenie dziecięce), jest to choroba zakaźna, wirusowa przenoszona drogą fekalno-oralną, więc wystarczy kontakt z przedmiotami, których chory dotykał, żeby doszło do zakażenia (w wyniku porażenia neuronów znajdujących się w rdzeniu kręgowym lub podstawie mózgu dochodzi do bezpośredniego zagrożenia życia) ${ }^{1}$ (Światowa Organizacja Zdrowia, 2017, kwiecień). W czasie konfliktów zbrojnych wzrasta też ryzyko zakażenia się HIV, co spowodowane jest brakiem bezpieczeństwa w punktach medycznych, brakiem dostępu do pod-

\footnotetext{
${ }^{1}$ W 2015 r. zgłoszono pierwsze zachorowania na poliomyelitis blisko granicy z Polską.
} 
stawowej opieki medycznej oraz zwiększonym ryzykiem niebezpiecznych kontaktów seksualnych. Rada Bezpieczeństwa ONZ w rezolucji nr 1308 uznała, że „pandemia HIV/AIDS zaostrzana jest przez przemoc i niestabilne warunki, które zwiększają ryzyko narażenia na tę chorobę poprzez duże przemieszczanie się ludności” (Rada Bezpieczeństwa Organizacji Narodów Zjednoczonych, 2000).

Konflikt na wschodzie Ukrainy wywiera znaczny wpływ na zdrowie psychiczne populacji. Wiele osób doświadcza przymusowego przesiedlenia $^{2}$, odłączenia od rodziny, niemożliwości kontynuacji pracy czy edukacji oraz strachu przed obrażeniami czy śmiercią. Takie warunki stwarzają podwyższone ryzyko rozwoju zaburzeń psychicznych, szczególnie dla osób, u których występowały one już wcześniej. Sytuację często pogarsza niedostateczny dostęp do ośrodków opieki zdrowotnej (International Alert, GIP-Tbilisi, London School of Hygiene and Tropical Medicine, 2017).

Zaopatrzenie w bieżącą wodę w okolicach, w których toczą się walki również stanowi problem (Wysoki Komisarz Narodów Zjednoczonych do spraw Praw Człowieka, 2017, 15 marca, s. 12-13). Na początku 2017 r. Doniecka Stacja Filtracyjna została uszkodzona w wyniku walk i pozostała nieczynna przez 45 dni. Cywile mieszkający po obu stronach linii rozgraniczenia byli pozbawieni bieżącej wody. W tej samej okolicy jeden z wodociągów południowego Donbasu był nieczynny przez ponad cztery miesiące, wpływając na braki w dostawie wody dla prawie 800 tys. ludzi. W sumie 3 mln osób zostało pozbawionych bieżącej wody w pierwszej połowie 2017 r. (Biuro Narodów Zjednoczonych ds. Koordynacji Pomocy Humanitarnej, 2017, s. 3). W czerwcu 2017 r. pracownicy przepompowni w południowym Donbasie zostali zmuszeni do opuszczenia stanowisk pracy, co skutkowało pozbawieniem dostępu do bieżącej wody kolejnych 350 tys. osób. Działania mediacyjne Międzynarodowego Komitetu Czerwonego Krzyża doprowadziły do podpisania porozumienia o utworzeniu stref bezpieczeństwa wokół przepompowni Vasilevka oraz Donieckiej Stacji Filtracyjnej (Międzynarodowy Komitet Czerwonego Krzyża, 2017,

${ }^{2}$ Wg danych ze wspólnego raportu International Alert, GIP-Tbilisi i London School of Hygiene and Tropical Medicine 32\% osób przesiedlonych cierpi na zespół stresu pourazowego, u $22 \%$ z nich rozpoznano depresję, a u 18\% osób występowały zaburzenia lękowe. U 43\% badanych występowało więcej niż jedno zaburzenie psychiczne. 
21 lipca). Strefy te nie mogą być celem ataków, na ich terenie nie mogą przebywać żołnierze ani sprzęt wojskowy.

Dlaczego brak zaopatrzenia w bieżącą wodę stanowi zagrożenie bezpieczeństwa zdrowotnego? Są to warunki doskonałe do rozwoju i transmisji patogenów powodujących choroby biegunkowe (Escherichia coli, Salmonella, Vibrio cholerae, Campylobacter), które przy braku dostępu do podstawowej opieki medycznej i leków mogą doprowadzić do śmierci. Wirusowe zapalenie wątroby typu A to kolejna choroba, której sprzyja brak dostępu do wody poddanej skutecznym zabiegom dezynfekcyjnym. Może mieć ona cięższy przebieg u osób po 50. roku życia, z przewlekłą chorobą wątroby i niedożywionych (Juszczyk, 2015).

Brak czystej wody i towarzyszące temu choroby to nie jedyne zagrożenia bezpieczeństwa zdrowotnego, które mogą wyniknąć z ataku na stacje filtracyjne. Raport Wysokiego Komisarza do spraw Praw Człowieka informuje o uszkodzeniu w nocy z 3 na 4 listopada 2017 r. rurociągu z chlorem, którego wdychanie grozi śmiercią. Wyciek toksycznego, wysoce reaktywnego gazu mógłby spowodować katastrofę środowiskową. Bezpośrednie uderzenie w główny rurociąg lub w jedną z 900-kilogramowych butli służących do przechowywania gazu na terenie Donieckiej Stacji Filtracyjnej mogłoby doprowadzić do śmierci osób w promieniu 200 metrów (Wysoki Komisarz Narodów Zjednoczonych do spraw Praw Człowieka, 2017, 12 grudnia, s. 9-10).

Pod koniec 2017 r. na terenie Ukrainy ponad 2 mln osób pozbawionych było dostępu do podstawowej opieki zdrowotnej, podczas gdy w co drugiej rodzinie zamieszkałej w obszarze konfliktu znajdowała się osoba cierpiąca na chorobę przewlekłą. Szacuje się, że ok. 3,8 mln osób potrzebowało pomocy humanitarnej (Biuro Narodów Zjednoczonych ds. Koordynacji Pomocy Humanitarnej, 2016, s. 5-6), a zarówno Doniecka, jak i Ługańska Republika Ludowa odmówiła większości organizacji świadczącym pomoc humanitarną działalności na swoim terenie (Lekarze bez Granic, 2015, 24 października). W listopadzie 2016 r. została cofnięta akredytacja przedostatniej grupie pomocowej People in Need na terenie Donieckiej Republiki Ludowej, a zgromadzone zasoby zostały w całości przejęte przez separatystów. Obecnie jedyną organizacją świadczącą pomoc humanitarną na terenach zajętych przez separatystów jest Międzynarodowy Komitet Czerwonego Krzyża. 
Oprócz strat spowodowanych urazami czy zgonami konflikty zbrojne wyzwalają i stają się promotorami chorób zakaźnych. Złe warunki higieniczne, zniszczona infrastruktura, ograniczony dostęp do opieki medycznej, a także przymusowe przesiedlenia sprzyjają nowym zachorowaniom pogarszając ich przebieg i zwiększając umieralność. Przemoc oraz bezpośrednie zagrożenie dla życia są czynnikami, które w znacznym stopniu ograniczają lub wręcz uniemożliwiają niesienie pomocy poszkodowanym czy też stosowanie odpowiedniej profilaktyki w celu ograniczenia transmisji zakażeń. Zagrożenia bezpieczeństwa zdrowotnego Ukrainy mogą mieć konsekwencje w postaci transgranicznych zagrożeń zdrowia publicznego, które będą wymagać wielostronnej i wielosektorowej reakcji.

\section{PAULINA MARIA NOWICKA}

Warszawski Uniwersytet Medyczny

pnowicka@wum.edu.pl

\section{Bibliografia}

\section{Dokumenty i raporty}

Biuro Narodów Zjednoczonych ds. Koordynacji Pomocy Humanitarnej. (2016). 2017 Humanitarian needs overview: Ukraine. Pobrane z: https://reliefweb.int/sites/reliefweb.int/files/resources/humanitarian_needs_overview_2017_eng.pdf [dostęp 26.02.2018].

Biuro Narodów Zjednoczonych ds. Koordynacji Pomocy Humanitarnej. (2017). 2017 Humanitarian overview. Needs and response analysis. January-May 2017:Ukraine. Pobrane z: https:/www.humanitarianresponse.info/system/files/documents/files/ ukraine_humanitarian_overview_jan-may-2017_20170629.pdf [dostęp 27.02.2018].

Centralna Agencja Wywiadowcza. (2000). National Intelligence Estimate NIE99-17D: The Global Infectious Disease Threat and Its Implications for the United States. Pobrane z: https://www.dni.gov/files/documents/infectiousdiseases_2000.pdf [dostęp 17.02.2018].

Europejski Trybunał Obrachunkowy. (2016). Special Report: Dealing with serious cross-border threats to health in the EU: important steps taken but more needs to be done. Pobrane z: https://www.eca.europa.eu/Lists/ECADocuments/SR16_28/ SR_HEALTH_EN.pdf, [dostęp 17.02.2018].

Global Health Security Initiative. (2002). Ministerial Statement. Pobrane z: http:// www.ghsi.ca/english/statementlondonmar2002.asp [dostęp 17.02.2018]. 
Human Rights Council. (2017, 16 marca). Report of the Office of the United Nations High Commissioner for Human Rights on the human rights situation in Ukraine (16 November 2016 to 15 February 2017). Pobrane z: http://www.ohchr.org/EN/ HRBodies/HRC/RegularSessions/Session34/Documents/A_HRC_34_CRP.5_E. docx [dostęp 26.02.2018].

Human Rights Watch. (2015, maj). Attacks on health: Global report. Pobrane z: https:// www.hrw.org/sites/default/files/related_material/HHR\%20Attacks\%20on\%20 Hospitals\%20brochure\%200515\%20LOWRES.pdf [dostęp 26.02.2018].

International Alert, GIP-Tbilisi, London School of Hygiene and Tropical Medicine. (2017). Hidden burdens of conflict. Issues of mental health and access to services among internally displaced persons in Ukraine. Pobrane z: http://www.international-alert.org/sites/default/files/Ukraine_HiddenBurdensConflictIDPs_EN_2017. pdf [dostęp 27.02.2018].

Justice for peace in Donbas. (2017). Health care facilities in the ATO zone. Pobrane z: http://www.hfhr.pl/wp-content/uploads/2017/03/Healthcare-facilities.pdf [dostęp 26.02.2018].

Panel Wysokiego Szczebla ONZ. (2004, 2 grudnia). A more secure world: our shared responsibility. Pobrane z: http://daccess-ods.un.org/access.nsf/Get?OpenAgent\& $\mathrm{DS}=\mathrm{A} / 59 / 565 \&$ Lang=E [dostęp 16.02.2018].

Rada Bezpieczeństwa Organizacji Narodów Zjednoczonych. (2000, 17 lipca). Rezolucja nr 1308 w sprawie pandemii HIV/AIDS oraz międzynarodowych operacji pokojowych. Pobrane z: http://www.unaids.org/sites/default/files/sub_landing/ files/20000717_un_scresolution_1308_en.pdf [dostęp 17.02.2018].

Safeguarding Health in Conflict. (2016). No protection, no respect. Health workers and health facilities under attack 2015 and early 2016. Pobrane z: https://www.safeguardinghealth.org/sites/shcc/files/SHCC2016final.pdf [dostęp 26.02.2018].

Swiatowa Organizacja Zdrowia. (2007). A Safer Future: Global Public Health Security in the 21st Century, The World Health Report 2007. Pobrane z: http://www.who.int/ entity/whr/2007/whr07_en.pdf?ua=1 [dostęp 18.02.2018].

Światowa Organizacja Zdrowia. (2016, 26 sierpnia). WHO's strategic role in humanitarian response in Ukraine. Pobrane z: http://www.who.int/hac/crises/ukr/ ukraine-who-strategic-role-humaitarian-response-august2016.pdf?ua=1 [dostęp 26.02.2018].

Światowa Organizacja Zdrowia. (2017). Global tuberculosis report 2017. Pobrane z: http://www.who.int/tb/publications/global_report/en/ [dostęp 26.02.2018].

Światowa Organizacja Zdrowia. (2017, 22 września). Report on BCG vaccine use for protection against mycobacterial infections including tuberculosis, leprosy, and other nontuberculous mycobacteria (NTM) infections. Pobrane z: http://www. who.int/immunization/sage/meetings/2017/october/1_BCG_report_revised_ version_online.pdf [dostęp 26.02.2018].

Światowe Zgromadzenie Zdrowia. (1946, 22 lipca). Konstytucja Światowej Organizacji Zdrowia. Pobrane z: http://prawo.sejm.gov.pl/isap.nsf/download.xsp/ WDU19480610477/O/D19480477.pdf [dostęp 10.02.2018]. 
Ukrainian Helsinki Human Rights Union. (2016). Access to humanitarian aid under conditions of armed conflict in the east of Ukraine. Pobrane $\mathrm{z}$ : https://helsinki. org.ua/wp-content/uploads/2016/06/Pravo-na-humdopomohu_Engl.pdf [dostęp 26.02.2018].

Światowe Zgromadzenie Zdrowia. (2001). Global health security: epidemic alert and response. Pobrane z: http://apps.who.int/iris/bitstream/10665/78789/1/ea54r14.pdf [dostęp 27.12.2017].

Wysoki Komisarz Narodów Zjednoczonych do spraw Praw Człowieka. (2017, 15 marca). Report on the human rights situation in Ukraine: 16 November 2016 to 15 February 2017. Pobrane z: http://www.un.org.ua/images/stories/17th_HRMMU_Report_ENG.pdf [dostęp 26.02.2018].

Wysoki Komisarz Narodów Zjednoczonych do spraw Praw Człowieka. (2017, 13 czerwca). Report on the human rights situation in Ukraine: 16 February to 15 May 2017. Pobrane z: http://www.ohchr.org/Documents/Countries/UA/UAReport18th_EN.pdf [dostęp 26.02.2018].

Wysoki Komisarz Narodów Zjednoczonych do spraw Praw Człowieka. (2017, 12 września). Report on the human rights situation in Ukraine: 16 May to $15 \mathrm{Au}$ gust 2017. Pobrane z: http://www.ohchr.org/Documents/Countries/UA/UAReport19th_EN.pdf [dostęp 26.02.2018].

Wysoki Komisarz Narodów Zjednoczonych do spraw Praw Człowieka. (2017, 12 grudnia). Report on the human rights situation in Ukraine: 16 August to 15 November 2017. Pobrane z: http://www.ohchr.org/Documents/Countries/UA/UAReport20th_EN.pdf [dostęp 26.02.2018].

\section{Monografie}

Czaputowicz, J. (2012). Bezpieczeństwo międzynarodowe: współczesne koncepcje. Warszawa: Wydawnictwo Naukowe PWN.

Elbe, S. (2010). Security and global health. Cambridge: Polity Press.

Juszczyk, J. (2015). Ostre wirusowe zapalenie wątroby (WZW). W: P. Gajewski (red.), Interna Szczeklika (1112-1115). Kraków: Medycyna Praktyczna.

Pawłowski, J. (red.). (2017). Podstawy bezpieczeństwa narodowego państwa. Warszawa: Wydawnictwo Akademii Sztuki Wojennej.

Rushton, S., Youde, J. (2015). Routledge Handbook of Global Health Security. Nowy Jork: Routledge.

Williams, P.D. (red.). (2012). Studia bezpieczeństwa. Kraków: Wydawnictwo Uniwersytetu Jagiellońskiego.

Wojtczak, A. (2009). Zdrowie publiczne wyzwaniem dla systemów zdrowia XXI wieku. Warszawa: Wydawnictwo Lekarskie PZWL.

\section{Artykuły naukowe}

Aldis, W. (2008). Health security as a public health concept: a critical analysis. Health Policy and Planning, 23(6), 369-375. 
Holt, E. (2014). Ukraine: health workers fear for their safety. The Lancet, 384(9945), 735.

Holt, E. (2015). Health care collapsing amid fighting in east Ukraine. The Lancet, 385(9967), 494.

Lekhan, V.N., Rudiy V.M., Shevchenko, M.V., Nitzan Kaluski, D., Richardson, E. (2015). Ukraine: Health system review. Health Systems in Transition, 17(2), 1-153.

\section{Inne źródła}

Human Rights Watch. (2014, 5 sierpnia). Ukraine: Insurgents Disrupt Medical Services. Pobrane z: https://www.hrw.org/news/2014/08/05/ukraine-insurgents-disrupt-medical-services [dostęp 26.02.2018].

Human Rights Watch. (2017, 24 maja). Hospitals, Health Workers Under Attack. Pobrane z: https://www.hrw.org/news/2017/05/24/hospitals-health-workers-underattack [dostęp 26.02.2018].

Lekarze bez Granic. (2014, 29 sierpnia). Ukraine: Effects of conflict spreading whilst health system struggles to cope. Pobrane z: http://www.msf.org/en/article/ ukraine-effects-conflict-spreading-whilst-health-system-struggles-cope [dostęp 26.02.2018].

Lekarze bez Granic. (2015, 24 października). Ukraine: Immediate termination of MSF medical activities in Donetsk will have life-threatening consequences for thousands of people. Pobrane z: http://www.msf.org/en/article/ukraine-immediatetermination-msf-medical-activities-donetsk-will-have-life-threatening [dostęp 26.02.2018].

Lekarze bez Granic. (2016, 5 lipca). Ukraine: „We are lost here and very scared”. Pobrane z: http://www.msf.org/en/article/ukraine-\%E2\%80\%9Cwe-are-lost-hereand-very-scared\%E2\%80\%9D [dostęp 26.02.2018].

Międzynarodowy Komitet Czerwonego Krzyża. (2017, 21 lipca). Ukraine: ICRC welcomes agreement on safety zones. Pobrane z: https://www.icrc.org/en/document/ ukraine-icrc-welcomes-agreement-safety-zones [dostęp 26.02.2018].

Światowa Organizacja Zdrowia. (2017, kwiecień). Poliomyelitis. Pobrane z: http:// www.who.int/topics/poliomyelitis/en/ [dostęp 26.02.2018]. 